\title{
ARCHIVES DÉPARTEMENTALES DE L'ARDÈCHE. - Répertoire des archives du collège de Tournon (1536-1790) Série D
}

Par Nathalie Meut, sous la direction de Dominique Dupraz. / Préface de Dominique Julia. - Privat : Archives départementales de l'Ardèche, 2002. $-151 \mathrm{p}$.

\section{Marcel Grandière}

\section{(2) OpenEdition} Journals

Édition électronique

URL : https://journals.openedition.org/histoire-education/371

DOI : 10.4000/histoire-education.371

ISSN : 2102-5452

Éditeur

ENS Éditions

\section{Édition imprimée}

Date de publication : 1 janvier 2003

Pagination : 145-146

ISBN : 2-7342-0946-2

ISSN : 0221-6280

Référence électronique

Marcel Grandière, «ARCHIVES DÉPARTEMENTALES DE L'ARDĖCHE. - Répertoire des archives du collège de Tournon (1536-1790) Série D», Histoire de l'éducation [En ligne], 97 | 2003, mis en ligne le 18 mai 2009, consulté le 20 mai 2021. URL : http://journals.openedition.org/histoire-education/371 ; DOI : https://doi.org/10.4000/histoire-education.371

Ce document a été généré automatiquement le 20 mai 2021.

(c) Tous droits réservés 


\section{ARCHIVES DÉPARTEMENTALES DE L'ARDÈCHE. - Répertoire des archives du collège de Tournon (1536-1790) Série D}

Par Nathalie Meut, sous la direction de Dominique Dupraz. / Préface de Dominique Julia. - Privat : Archives départementales de l'Ardèche, 2002. $-151 \mathrm{p}$.

\section{Marcel Grandière}

\section{RÉFÉRENCE}

ARCHIVES DÉPARTEMENTALES DE L'ARDÈCHE. - Répertoire des archives du collège de Tournon (1536-1790) Série D, par Nathalie Meut, sous la direction de Dominique Dupraz. / Préface de Dominique Julia. - Privat : Archives départementales de l'Ardèche, 2002. $-151 \mathrm{p}$.

1 Les archives qui font l'objet de ce classement concernent la période 1536 - date de fondation du collège par le cardinal François de Tournon - 1790. Elles proviennent de plusieurs versements $(1886,1889,1912)$ qui avaient donné lieu à un premier classement (inachevé) et à un inventaire dactylographié rédigé en 1952 par Jacques de Font Réaulx. Le présent répertoire a le grand avantage de reprendre et de présenter l'ensemble du fonds déposé aux archives départementales relatives au collège de Tournon sous l'Ancien Régime.

2 Ce fonds est classé en deux parties, l'une relative à l'établissement de Tournon (D7/ D161), l'autre au séminaire de Broé et aux quatre prieurés unis au collège (D162/D276). Le répertoire ouvre également sur des "sources complémentaires" (pp.17-22) concernant le collège, situées dans d'autres séries des archives de l'Ardèche, aux Archives nationales, ou dans les archives des départements voisins et de la ville de 
Lyon. Le chercheur devra compléter avec les séries $\mathrm{L}$ et $\mathrm{T}$ des fonds ardéchois (on trouve souvent dans ces séries les résultats des enquêtes sur les collèges, les actes des saisies opérées sous la Révolution, des documents des périodes antérieures), avec les archives romaines de la Compagnie de Jésus, et sans doute aussi avec les fonds notariaux (sous-série $2 \mathrm{E}$ ) qui révèlent souvent de vraies richesses. Le répertoire est précédé d'une préface de Dominique Julia et d'une introduction de Nathalie Meut, suivie d'un index des noms de personnes, de lieux et de matières.

3 Les archives du collège de Tournon sont d'un grand intérêt. À cause de l'importance du collège, d'abord, "l'un des plus importants de la France d'Ancien Régime », selon D. Julia, l'une des pièces maîtresses du dispositif catholique (le cardinal de Tournon, après la période d'administration laïque, confie son collège aux jésuites en 1561) face aux avancées protestantes dans les pays du Rhône. L'importance du collège est liée aussi à la qualité de l'enseignement, au rôle joué dans la diffusion des sciences mathématiques dans la compagnie, suivant les efforts de Clavius dans le collège romain pour former des jésuites qui soient présents aux frontières scientifiques du moment. Après la chute des jésuites en 1762, et la période du bureau d'administration, selon l'édit de février 1763 , le collège connaît une dernière période remarquable avec l'arrivée des oratoriens et la promotion de Tournon comme collège militaire en 1776.

4 La richesse des archives fait évidemment l'intérêt principal de ce classement. La thématique retenue (variable selon les parties) n'étonnera guère les chercheurs: généralités, bâtiments, mobilier, personnel, comptabilité-gestion, procédures, élèves, bénéfices, divers. Elle rappelle qu'un collège est d'abord une entreprise totalement imbriquée dans la société d'Ancien Régime, dépassant le seul cadre scolaire : les sources comptables et les nombreuses correspondances permettent d'envisager une étude économique de l'établissement et d'appréhender les stratégies éducatives des familles.

Ce répertoire est un outil de travail remarquable pour les historiens. On ne peut que se réjouir de sa publication, et espérer que de semblables instruments de recherche voient bientôt le jour.

\section{AUTEUR}

\section{MARCEL GRANDIÈRE}

